\title{
In Vitro Permeation Characteristics of Itraconazole from Oil Drops and Ophthalmic Ointment Through Excised Goat And Sheep Corneas.
}

\author{
Biswaranjan Mohanty ${ }^{1}$, Sagar K. Mishra ${ }^{2}$, Dipak K. Majumdar ${ }^{3 *}$ \\ ${ }^{I}$ Seemanta Institute of Pharmaceutical Sciences, Jharpokharia, Mayurbhanj, Orissa-757 086 \\ ${ }^{2}$ University Department of Pharmaceutical Sciences, Utkal University, Bhubaneswar, India \\ ${ }^{3}$ Department of Pharmaceutics, Delhi Institute of Pharmaceutical Sciences and Research, Formerly College of \\ Pharmacy, University of Delhi, Pushp Vihar, Sector III, New Delhi-110017, India
}

\begin{abstract}
In vitro transcorneal permeation of itraconazole from oil drops and ophthalmic ointments was studied using freshly excised goat and sheep corneas. Permeation of itraconazole from castor oil was found maximum and minimum with kardi oil formulation. The higher permeation of itraconazole from castor oil formulation could be attributed to the lower partition coefficient of drug between oil and aqueous phase. The addition of benzyl alcohol, a preservative, in oil drops, increased the permeation of itraconazole. Partition experiments indicated increased partitioning of itraconazole in the aqueous phase in the presence of benzyl alcohol. The addition of phenyl mercuric acetate, phenyl mercuric nitrate and thiomersal as preservative, in castor oil drop decreased the permeation of itraconazole. Corneal hydration was within the desired limit below $80 \%$. Permeation of itraconazole from ointment containing dissolved drug was higher than the ointment containing solid drug. In antifungal study, the castor oil formulation showed maximum zone of inhibition against Candida albicans. Stability study conducted at $40^{\circ} \mathrm{C}$ and $70 \%$ RH indicated the formulations as quite stable to ensure 2 years shelf life.
\end{abstract}

Keywords: - itraconazole, partition coefficient, permeation, preservative, stability.

\section{Introduction}

Topical ocular fungal infections can be effectively treated with ocular drug delivery rather than using oral delivery of antifungal drugs. Ophthalmic mycosis is a major cause of vision loss and morbidity and can be life-threatening.[1-2] Fungal keratitis is one major cause of ophthalmic mycosis.[3] Current strategies for the treatment of fungal corneal infections rely on locally administered antifungal agents, usually by the topical route. [4-7] The triazoles, a new group of agents derived from the imidazoles, show promising antifungal activity. Two members of the group, fluconazole and itraconazole, have received the most attention. [8,9] Itraconazole is poorly soluble in water. Protein binding is high, tissue levels are inferior to those achieved with fluconazole.[9] The mechanism of action of itraconazole relates to its binding of fungal cytochrome P-450 with resultant inhibition of ergosterol synthesis, and perturbation of membrane bound enzyme function and membrane permeability. Eye drops are the most economical and efficient way of delivering medicament into the eye.[10] The major impediment to the bioavailability of topically applied ophthalmic drugs is incomplete absorption due to nasolacrimal drainage. One approach to overcome this problem has been through prolonging the ocular contact time of the medication. Increased contact time of the drug may be achieved by formulating the drug as oil solution or ophthalmic ointment. The oil drop and ointment formulation provides prolonged therapeutic action due to increased ocular contact time. Earlier studies with pilocarpine, [11] ketorolac,[12,13] diclofenac [14] and moxifloxacin[15] revealed higher ocular penetration of drug from oily solutions. There is no information available on corneal permeation of itraconazole from oil-based ocular drops or ophthalmic ointment. Therefore, the present study focuses on the corneal permeation of itraconazole from oily solution and ophthalmic ointment using freshly excised goat and sheep corneas and on the stability of the formulations.

\subsection{Materials}

\section{Materials And Methods}

Itraconazole was obtained from Jubilant Organosys Ltd., New Delhi as a gift. Benzyl alcohol (BA) (E. Merck, India), phenylmercuric acetate (PMA) (Himedia Lab Pvt. Ltd, Mumbai), phenylmercuric nitrate (PMN) (Himedia Lab Pvt. Ltd, Mumbai) and thiomersal (THM) (Sisco research lab.Pvt. Ltd) were used as preservative. Refined edible oils used in the experiment were arachis oil (Jyoti Ind. Gujarat), castor oil (B.D.Pharmaceuticals, Kolkata.), cottonseed oil (Sangrur Agro. Ltd., Punjab ), kardi oil (Safflower) ( J. Marico Ltd..,Mumbai, India) linseed oil ( V.M.Oils Pvt. Ltd, Kolkata.), olive oil (Salov SpA, Italy) sesame oil ( V.M.Oils Pvt. Ltd, Kolkata ), soybean oil (Adani Wilmar Ltd., Ahmadabad, Gujarat) and sunflower oil (Adani Wilmar Ltd., Ahmadabad, 
Gujarat. ). Malt extract (Loba Chemie, Mumbai), yeast extract (Loba Chemie, Mumbai), peptone (Loba Chemie, Mumbai), glucose (Finar Chemical, Ahmadabad and agar (Ranbaxy Lab., Punjab) were purchased. Freeze-dried microbial cultures of Candida albicans (MTCC NO 3017) was purchased from Institute of Microbial Technology, Chandigarh, India. All other chemicals were of analytical grade. Fresh eyeballs of goat and sheep were obtained from local butchers shop (Baripada, Odisha, India) within 1 hour of slaughtering of animals. The method of dissection of cornea and the apparatus used in the permeation studies were the same as published elsewhere. [16]

\subsection{Solubility of itraconazole in oils}

An excess amount of itraconazole was added to oils to prepare a saturated solution at $40^{\circ} \mathrm{C}$. The solution of itraconazole was then cooled and left overnight at $4^{0} \mathrm{C}$. The solution was subsequently centrifuged at $4^{0} \mathrm{C}$ at $4500 \mathrm{rpm}$ (Remi Equipments Ltd, Mumbai, India). Five ml of clear supernatant was subjected to 4-5 successive extraction with $50 \mathrm{ml}$ of $0.1 \mathrm{~N} \mathrm{HCl}$ and analyzed for itraconazole content by measuring absorbance in a spectrophotometer (UV-1700, Shimadzu) at $266 \mathrm{~nm}$.

\subsection{Determination of partition coefficient}

Equal volume of each oil formulation and phosphate buffer (Sorenson's phosphate buffer, $\mathrm{pH}$ 7.4) were continuously shaken at room temperature in a reciprocating shaker at $200 \mathrm{rpm}$ (Satyam equipments, New Delhi) for two hours. Itraconazole content in aqueous phase was analyzed and partition coefficients were calculated. The experiments were done with triplicate sample of each formulation. The result was expressed as mean \pm SD.

\subsection{Methods}

\subsubsection{Preparation of test solutions}

(a) To study the effect of different oily vehicles on transcorneal permeation of itraconazole, $0.01 \% \mathrm{w} / \mathrm{v}$ oily solutions of drug were formulated in arachis, castor, cottonseed, kardi, linseed, olive, sesame, soybean and sunflower oils.

(b) To determine the effect of preservative on transcorneal permeation of itraconazole, oil drops were prepared with the addition of $0.5 \% \mathrm{v} / \mathrm{v}$ benzyl alcohol. Similarly $0.01 \% \mathrm{w} / \mathrm{v}$ drops of itraconazole in castor oil with PMA $(0.002 \% \mathrm{w} / \mathrm{v})$, PMN $(0.002 \% \mathrm{w} / \mathrm{v})$ or THM $(0.005 \% \mathrm{w} / \mathrm{v})$ were prepared.

\subsubsection{Preparation of ophthalmic ointment}

Simple eye ointment base specified in IP [17] was selected for this study. Wool fat (10\%) and white soft paraffin $(80 \%)$ were melted together and liquid paraffin $(10 \%)$ was added to it. The hot mixture was then filtered and allowed to cool to room temperature to have the base with smooth semisolid consistency. The drug was incorporated to the base as a solid using process-1(Type-A) or as an aqueous solution using process2(Type-B). Aqueous solution of itraconazole was prepared with beta-cyclodextrin in a drug to beta-cyclodextrin ratio $1: 20$.

\subsection{Method of analysis}

Itraconazole from oil drops and ointments were extracted by five successive extractions with $50 \mathrm{ml}$ of $0.1 \mathrm{~N} \mathrm{HCl}$. The aqueous phases were pooled, filtered and drug content was analyzed by measuring absorbance in a spectrophotometer at $266 \mathrm{~nm}$.

\subsection{Permeation experiment}

Freshly excised cornea was mounted between clamped donor and receptor compartments of an all glass modified Franz diffusion cell in such a way that its epithelial surface faced the donor compartment. The corneal area available for diffusion was $0.64 \mathrm{~cm}^{2}$. The receptor compartment was filled with $11.4 \mathrm{ml}$ of freshly prepared bicarbonate ringer solution ( $\mathrm{pH} 7.4$ ). The donor sample ( 1 milliliter of oil solution or 0.5 grams of ointment) was placed on the cornea. The opening of the donor compartment was sealed with a cover slip and the receptor compartment was maintained at $37^{\circ} \mathrm{C}$ with constant stirring, using a Teflon-coated magnetic stir bead. Permeation study was continued for 120 minutes. Sample was withdrawn from receptor compartment and analyzed for itraconazole content using spectrophotometer at $266 \mathrm{~nm}$. Results were expressed as amount permeated and percentage permeation. The permeation (\%) or in vitro ocular availability was calculated as follow;

Permeation $(\%)=($ Amount of drug permeated in receptor / Initial amount of drug in donor) X 100--------(1) At the end of the experiment, the scleral tissue was removed from cornea; its epithelial surface was wiped with filter paper and weighed. The cornea was then soaked in one $\mathrm{ml}$ methanol, dried overnight at $90^{\circ} \mathrm{C}$, and reweighed. From the difference in weight, corneal hydration (\%) was calculated. 


\subsection{Antifungal activity}

The antifungal activity of the oil drops was evaluated against Candida albicans. The fungal strain was maintained in agar slants (malt yeast agar media). Antifungal activity was evaluated by paper disc diffusion method (IP 1985). The medium used for the antifungal activity was same as the maintenance medium of respective fungi. The slant of the microorganism was washed with sterile saline and the cell suspension was further diluted with sterile saline. The cell suspension $(0.1 \mathrm{ml})$ was used to inoculate $100 \mathrm{ml}$ of molten media (sterile). This inoculated medium was poured in $20 \mathrm{ml}$ quantities into $9 \mathrm{~cm}$ petridishes (borosil) and the medium was allowed to solidify. Sterile paper discs of $4 \mathrm{~mm}$ diameter (made from Whatman No.1 filter paper) were soaked in the oil formulation and each disc in triplicate was placed in the inoculated media contained in the petridish. Each petridish was incubated for 2 days at $25^{\circ} \mathrm{C}$. After specified period of incubation, the clear zone of inhibition in each petridish was measured in $\mathrm{mm}$.

\subsection{Stability testing}

The amber colored, USP type-I, $2 \mathrm{ml}$ glass ampoules were washed with tap water and distilled water, followed by drying in an oven. The oily ophthalmic solutions of itraconazole were filled into dried glass ampoules and heat-sealed. The stability testing on ophthalmic formulations was conducted by storage at $40^{\circ} \mathrm{C}$ and $75 \% \mathrm{RH}$ for six months. The samples of ophthalmic formulations were withdrawn at 0 day, 6 weeks, 3 months and six months and analyzed for appearance and itraconazole content.

\section{Results And Discussion}

TABLE 1 shows the solubility of itraconazole in different oils and its partition characteristics. Solubility was measured at $4^{0} \mathrm{C}$. Itraconazole was found to have the maximum solubility $(\% \mathrm{w} / \mathrm{v})$ in castor oil (0.035) followed by sesame (0.017) and linseed (0.016). In the rest of the oils like arachis, cottonseed, soybean, olive, kardi and sunflower, the solubility was between 0.011 and $0.014 \% \mathrm{w} / \mathrm{v}$. Based on the solubility of itraconazole in different oils, solutions were prepared in $0.01 \% \mathrm{w} / \mathrm{v}$ concentration to avoid the precipitation due to climatic changes. The partition coefficient of itraconazole between oil and phosphate buffer ( $\mathrm{pH} 7.4)$ was found to be maximum with kardi oil followed by arachis and soybean oil, while minimum partition coefficient was observed with castor oil. Benzyl alcohol, a commonly used preservative, was added to oil formulations at $0.5 \% \mathrm{v} / \mathrm{v}$ concentration. Partition experiments showed higher partitioning of drug from the oil to the aqueous phase in the presence of benzyl alcohol. Partitioning of itraconazole from castor oil to aqueous phase was decreased in the presence of PMA, PMN and THM.

The permeation of itraconazole from oil drops with and without benzyl alcohol through goat corneas are shown in the TABLE 2.Results reveal the maximum permeation of itraconazole $(0.0049 \mathrm{mg}, 4.838 \%)$ from castor oil

Table 1: Solubility of itraconazole in different edible oils and partition characteristics of itraconazole from oil drops $(0.01 \% \mathrm{w} / \mathrm{v})$ with or without BA $(0.05 \% \mathrm{v} / \mathrm{v})$ and castor oil drop with PMA $(0.002 \% \mathrm{w} / \mathrm{v})$, PMN

$(0.002 \% \mathrm{w} / \mathrm{v})$, THM $(0.005 \% \mathrm{w} / \mathrm{v})$.

\begin{tabular}{|c|c|c|c|c|c|c|}
\hline \multirow[t]{2}{*}{ Oil } & \multirow{2}{*}{$\begin{array}{l}\text { Solubility } \\
\% \text { w / v }\end{array}$} & \multicolumn{5}{|c|}{ Partition coefficient } \\
\hline & & Without & with BA & with PMA & with PMN & with THM \\
\hline Arachis & $0.014 \pm 0.002$ & $15.52 \pm 0.92 \dagger$ & $1.68 \pm 0.05$ & & & \\
\hline Castor & $0.035 \pm 0.001$ & $2.56 \pm 0.12$ & $1.66 \pm 0.01$ & $4.03 \pm 0.03$ & $7.48 \pm 0.07$ & $6.37 \pm 0.02$ \\
\hline Cottonseed & $0.014 \pm 0.001$ & $10.65 \pm 0.54 \dagger$ & $2.35 \pm 0.10 *$ & & & \\
\hline Kardi & $0.013 \pm 0.001$ & $20.84 \pm 0.75 \dagger$ & $4.67 \pm 0.06 *$ & & & \\
\hline Linseed & $0.016 \pm 0.003$ & $6.88 \pm 0.44 \dagger$ & $2.69 \pm 0.07 *$ & & & \\
\hline Olive & $0.014 \pm 0.002$ & $7.10 \pm 0.42 \uparrow$ & $4.11 \pm 0.08 *$ & & & \\
\hline Sesame & $0.017 \pm 0.002$ & $8.47 \pm 0.24 \dagger$ & $4.58 \pm 0.10^{*}$ & & & \\
\hline Soybean & $0.014 \pm 0.003$ & $13.25 \pm 0.31 \dagger$ & $2.56 \pm 0.03 *$ & & & \\
\hline sunflower & $0.011 \pm 0.000$ & $10.19 \pm 0.56 \dagger$ & $3.23 \pm 0.21 *$ & & & \\
\hline
\end{tabular}


Table 2: In Vitro transcorneal permeation of itraconazole from oil based drops $(0.01 \% \mathrm{w} / \mathrm{v})$ with and without benzyl alcohol through freshly excised goat corneas.

\begin{tabular}{lcccccc}
\hline Oils & \multicolumn{3}{c}{ without benzyl alcohol } & \multicolumn{3}{c}{ with benzyl alcohol } \\
\cline { 2 - 6 } & $\begin{array}{c}\text { Amount } \\
\text { permeated } \\
(\mathrm{mg} / 120 \mathrm{~min})\end{array}$ & $\begin{array}{c}\text { Permeation } \\
(\%)\end{array}$ & $\begin{array}{c}\text { Corneal } \\
\text { hydration } \\
(\%)\end{array}$ & $\begin{array}{c}\text { Amount } \\
\text { permeated } \\
(\mathrm{mg} / 120 \mathrm{~min})\end{array}$ & $\begin{array}{c}\text { Permeation } \\
(\%)\end{array}$ & $\begin{array}{c}\text { Corneal } \\
\text { hydration } \\
(\%)\end{array}$ \\
\hline Arachis & 0.00208 & 2.040 & 76.11 & $0.00527 *$ & 5.161 & 77.56 \\
& \pm 0.00056 & \pm 0.550 & \pm 0.17 & \pm 0.00042 & \pm 0.416 & \pm 0.43 \\
Castor & $0.00490 \dagger$ & 4.838 & 78.45 & $0.00576 *$ & 5.685 & 79.38 \\
& \pm 0.00064 & \pm 0.554 & \pm 0.38 & \pm 0.00056 & \pm 0.554 & \pm 0.22 \\
Cottonseed & $0.00257 \dagger$ & 2.627 & 77.69 & 0.00478 & 4.878 & 78.48 \\
& \pm 0.00037 & \pm 0.650 & \pm 0.36 & \pm 0.00037 & \pm 0.375 & \pm 0.27 \\
Kardi & 0.00110 & 1.076 & 75.81 & 0.00368 & 3.586 & 76.68 \\
& \pm 0.00037 & \pm 0.359 & \pm 0.71 & \pm 0.00074 & \pm 0.717 & \pm 0.22 \\
Linseed & $0.00343 \dagger$ & 3.402 & 77.97 & 0.00429 & 4.252 & 78.44 \\
& \pm 0.00042 & \pm 0.421 & \pm 0.64 & \pm 0.00056 & \pm 0.557 & \pm 0.13 \\
Olive & $0.00319 \dagger$ & 3.214 & 78.55 & 0.00392 & 3.956 & 79.41 \\
& \pm 0.00042 & \pm 0.428 & \pm 0.56 & \pm 0.00056 & \pm 0.566 & \pm 0.47 \\
Sesame & $0.00282 \dagger$ & 2.854 & 77.39 & 0.00380 & 3.847 & 79.06 \\
& \pm 0.00042 & \pm 0.430 & \pm 0.24 & \pm 0.00056 & \pm 0.569 & \pm 0.90 \\
Soybean & $0.00223 \dagger$ & 2.345 & 77.13 & 0.00441 & 4.443 & 78.56 \\
& \pm 0.00056 & \pm 0.566 & \pm 0.16 & \pm 0.00074 & \pm 0.741 & \pm 0.74 \\
Sunflower & $0.00270 \dagger$ & 2.727 & 76.57 & 0.00405 & 4.091 & 78.33 \\
& \pm 0.00042 & \pm 0.429 & \pm 0.72 & \pm 0.00074 & \pm 0.744 & \pm 0.97 \\
\hline
\end{tabular}

Values are mean $\pm \mathrm{SD}$ of three observations in each group.

$\dagger$ Statistically significant $(p<0.05)$ compared with kardi oil $(0.01 \% \mathrm{w} / \mathrm{v})$ without BA as determined by 1 -way ANOVA followed by Dunnett's test.

*Statistically significant $(p<0.05)$ compared with kardi oil $(0.01 \% \mathrm{w} / \mathrm{v})$ with BA as determined by 1-way ANOVA followed by Dunnett's test.

$(0.01 \% \mathrm{w} / \mathrm{v})$ and minimum $(0.0011 \mathrm{mg}, 1.076 \%)$ from kardi oil drop. The higher permeation of itraconazole from castor oil formulation could be attributed to the lower partition coefficient of drug between the oil and aqueous phase. On comparing the amount of itraconazole permeated from kardi oil with others, it was observed that significantly $(\mathrm{p}<0.05)$ higher permeability of itraconazole was provided by most of the oil formulation. Addition of benzyl alcohol $(0.5 \%)$, a preservative to the oil formulations resulted in increased permeation of itraconazole from all the formulations compared with the formulation without benzyl alcohol. The amount permeation of itraconazole was found maximum from castor oil with benzyl alcohol followed by arachis, cottonseed, soybean, linseed and olive oil with benzyl alcohol. The hydration level (\%) of goat cornea ( after 2 hours permeation) were found as $75.81 \pm 0.711$ to $78.45 \pm 0.377$ in oil formulation without benzyl alcohol and $76.68 \pm 0.219$ to $79.38 \pm 0.223$ in formulation containing benzyl alcohol. All the experiments showed corneal hydration below $80 \%$ showing no corneal damage.

Table 3: In Vitro transcorneal permeation of itraconazole from oil based drops $(0.01 \% \mathrm{w} / \mathrm{v})$ with and without benzyl alcohol through freshly excised sheep corneas.

\begin{tabular}{lccc|ccc}
\hline Oils & \multicolumn{2}{c}{ without benzyl alcohol } & \multicolumn{2}{c}{ with benzyl alcohol } \\
\cline { 2 - 6 } & $\begin{array}{c}\text { Amount } \\
\text { permeated } \\
(\mathrm{mg} / 120 \mathrm{~min})\end{array}$ & $\begin{array}{c}\text { Permeation } \\
(\%)\end{array}$ & $\begin{array}{c}\text { Corneal } \\
\text { hydration } \\
(\%)\end{array}$ & $\begin{array}{c}\text { Amount } \\
\text { permeated } \\
(\mathrm{mg} / 120 \mathrm{~min})\end{array}$ & $\begin{array}{c}\text { Permeation } \\
(\%)\end{array}$ & $\begin{array}{c}\text { Corneal } \\
\text { hydration } \\
(\%)\end{array}$ \\
\hline Arachis & 0.00172 & 1.680 & 77.45 & $0.00417^{*}$ & 4.080 & 78.53 \\
& \pm 0.00021 & \pm 0.208 & \pm 0.25 & \pm 0.00056 & \pm 0.550 & \pm 0.62 \\
Castor & $0.00441 \dagger$ & 4.355 & 78.20 & $0.00466^{*}$ & 4.596 & 79.40 \\
& \pm 0.00037 & \pm 0.363 & \pm 0.21 & \pm 0.00077 & \pm 0.755 & \pm 0.42 \\
Cottonseed & $0.00221 \dagger$ & 2.251 & 76.46 & 0.00368 & 3.752 & 77.32 \\
& \pm 0.00037 & \pm 0.375 & \pm 0.50 & \pm 0.00037 & \pm 0.375 & \pm 0.07 \\
Kardi & 0.00086 & 0.837 & 75.60 & 0.00221 & 2.151 & 76.81 \\
& \pm 0.00056 & \pm 0.548 & \pm 0.14 & \pm 0.00064 & \pm 0.621 & \pm 0.36 \\
Linseed & $0.00282 \dagger$ & 2.794 & 76.98 & 0.00331 & 3.280 & 78.04 \\
& \pm 0.00021 & \pm 0.210 & \pm 0.50 & \pm 0.00037 & \pm 0.364 & \pm 0.83
\end{tabular}




\begin{tabular}{lrrrrrr}
\hline & & & & & & \\
Olive & $0.00270 \dagger$ & 2.720 & 77.77 & 0.00306 & 3.090 & 78.89 \\
& \pm 0.00056 & \pm 0.566 & \pm 0.26 & \pm 0.00056 & \pm 0.566 & \pm 0.83 \\
Sesame & 0.00257 & 2.606 & 77.33 & 0.00294 & 2.978 & 78.80 \\
& \pm 0.00037 & \pm 0.372 & \pm 0.50 & \pm 0.00037 & \pm 0.372 & \pm 0.52 \\
Soybean & 0.00196 & 1.975 & 76.14 & 0.00331 & 3.332 & 78.48 \\
& \pm 0.00021 & \pm 0.214 & \pm 1.00 & \pm 0.00037 & \pm 0.370 & \pm 0.93 \\
Sunflower & $0.00233 \dagger$ & 2.355 & 75.74 & 0.00306 & 3.099 & 78.01 \\
& \pm 0.00056 & \pm 0.568 & \pm 0.56 & \pm 0.00118 & \pm 1.195 & \pm 0.87
\end{tabular}

Values are mean \pm SD of three observations in each group.

$\dagger$ Statistically significant $(p<0.05)$ compared with kardi oil $(0.01 \% \mathrm{w} / \mathrm{v})$ without BA as determined by 1 -way ANOVA followed by Dunnett's test.

*Statistically significant $(p<0.05)$ compared with kardi oil $(0.01 \% \mathrm{w} / \mathrm{v})$ with BA as determined by 1 -way ANOVA followed by Dunnett's test.

TABLE 3 shows the permeation of itraconazole from $0.01 \% \mathrm{w} / \mathrm{v}$ oil drops with benzyl alcohol and without benzyl alcohol through excised sheep corneas. Permeation of itraconazole from castor oil drop was found to be highest followed by linseed and olive oil. Addition of benzyl alcohol significantly $(\mathrm{p}<0.05)$ increased permeation of itraconazole from castor and arachis oil drop as compared with kardi oil drop. The increased corneal permeation from oil formulations through both goat and sheep corneas with benzyl alcohol could be attributed to lower partitioning of itraconazole to the oils. The hydration level $(\%)$ in sheep corneas were found as $75.74 \pm 0.557$ to $78.20 \pm 0.212$ in oil formulation without benzyl alcohol and $76.81 \pm 0.356$ to $79.40 \pm 0.419$ in formulation containing benzyl alcohol.

The corneal hydration level of mammalian cornea is between 75 to $80 \%$.[18] Post permeation corneal hydration was found to be in the normal range with all the oil drops. Addition of benzyl alcohol, a commonly used preservative in oil formulation increased the permeation of itraconazole from all the oil drops comparatively than oil drops without benzyl alcohol through both goat and sheep corneas.

TABLE 4 shows the permeation study of castor oil drop with the common preservatives like phenyl mercuric acetate $(0.002 \% \mathrm{w} / \mathrm{v})$, phenyl mercuric nitrate $(0.002 \% \mathrm{w} / \mathrm{v})$ and thiomersal $(0.005 \% \mathrm{w} / \mathrm{v})$. Addition of the PMA, PMN and THM to the castor oil formulation, significantly $(\mathrm{p}<0.05)$ reduced the permeation of itraconazole compared with castor oil drop without preservative. The decreased corneal permeation from oil formulations through both goat and sheep corneas with PMA, PMN and THM could be attributed to higher partitioning of itraconazole to the castor oil. The hydration level $(\%)$ were found as $78.98 \pm 0.754$ to $79.69 \pm$ 0.184 and $74.67 \pm 0.343$ to $78.88 \pm 0.584$ from castor oil drops with and without preservative in goat and sheep corneas respectively. No corneal damage was found from the above study.

Table 4: Effect of preservative on permeation of itraconazole from $0.01 \%$ castor oil drop through excised goat cornea and sheep cornea.

\begin{tabular}{lcccccc}
\hline Preservatives & \multicolumn{3}{c}{ Goat cornea } & \multicolumn{3}{c}{ Sheep cornea } \\
\cline { 2 - 6 } & $\begin{array}{c}\text { Amount } \\
\text { permeated } \\
(\mathrm{mg} / 120 \mathrm{~min})\end{array}$ & $\begin{array}{c}\text { Permeation } \\
(\%)\end{array}$ & $\begin{array}{c}\text { Corneal } \\
\text { hydration } \\
(\%)\end{array}$ & $\begin{array}{c}\text { Amount } \\
\text { permeated } \\
(\mathrm{mg} / 120 \mathrm{~min})\end{array}$ & $\begin{array}{c}\text { Permeation } \\
(\%)\end{array}$ & $\begin{array}{c}\text { Corneal } \\
\text { hydration } \\
(\%)\end{array}$ \\
\hline Control & 0.00490 & 4.84 & 78.45 & 0.00441 & 4.36 & 78.20 \\
& \pm 0.00064 & \pm 0.55 & \pm 0.38 & \pm 0.00037 & \pm 0.36 & \pm 0.21 \\
PMA & $0.00270 \dagger$ & 2.66 & 79.30 & $0.00208^{*}$ & 2.06 & 77.13 \\
& \pm 0.00042 & \pm 0.42 & \pm 0.33 & \pm 0.00056 & \pm 0.55 & \pm 0.75 \\
PMN & $0.00159 \dagger$ & 1.57 & 78.80 & $0.00172 *$ & 1.69 & 78.80 \\
& \pm 0.00042 & \pm 0.42 & \pm 0.44 & \pm 0.00056 & \pm 0.55 & \pm 0.44 \\
THM & $0.00196 \dagger$ & 1.94 & 78.98 & $0.00221^{*}$ & 2.18 & 74.67 \\
& \pm 0.00021 & \pm 0.21 & \pm 0.75 & \pm 0.00037 & \pm 0.36 & \pm 0.34 \\
\hline
\end{tabular}

Values are mean \pm SE of three observations in each group.

$\dagger$ Statistically significant $(p<0.05)$ compared with control as determined by 1-way ANOVA followed by Dunnett's test.

*Statistically significant $(p<0.05)$ compared with control as determined by 1-way ANOVA followed by Dunnett's test.

The most convenient route of delivering drugs to the eye is the topical application of an aqueous solution. From the aqueous solution, drug partition through the corneal epithelium, stroma and endothelium into the aqueous humour. The most demerit of topically applied aqueous drug solution is the loss of drug due to drainage, which results in lower ocular availability of drug and a therapeutic effect of shorter duration. One way of overcoming the problem is to apply the drug in the form of an oily solution. Vegetable oils like olive, castor and sesame oil are used as vehicle for oil-based drops.[19] It has been reported that in healthy subjects pilocarpine dissolved in castor oil has a greater degree and duration of effect on the pupil than the same amount of drug given in aqueous solution. Statistically significant drug effect have been noted for 24 hours after 
administration of oil based drops. [20] Keeping the same in view oil based drops of itraconazole were formulated in a number of vegetable oils. The concentration of itraconazole in the oil drops was decided depending on the solubility of drug in the respective oils. The partitioning phenomenon is an equilibrium process described by the apparent oil/water partition coefficient $(\mathrm{K}=\mathrm{Co} / \mathrm{Cw}$, where $\mathrm{Co}$ is the concentration of drug in organic phase in equilibrium and $\mathrm{Cw}$ is the concentration of drug in aqueous phase in equilibrium). Only that fraction of total drug concentration which present in aqueous phase, $\mathrm{f}$, could be absorbed

$$
\mathrm{f}=1+\alpha / 1+\mathrm{K} \alpha
$$

Where $\mathrm{K}$ is the apparent oil/water partition coefficient and $\alpha$ is the ratio $\mathrm{Vo} / \mathrm{Vw}$, the volume of the oil phase to that of the aqueous phase. The equation indicates that the fraction of drug available for absorption is controlled by the partition coefficient and the ratio of the two phases $(\alpha)$ and that it remains constant so long $\alpha$ is constant. Since $\mathrm{Vw}$ is a physiological parameter, it usually is constant and therefore the value of $\alpha$ is determined solely by the volume of oil phase. The rate of drug absorption is described by equation

$$
\mathrm{d}(\mathrm{C}) / \mathrm{dt}=\text { Ka. f. (Dt) }
$$

Where (Dt) is the total drug concentration in both phase and $\mathrm{Ka}$ is the absorption rate constant. The above discussion suggests that the rate of absorption of drug from oil solution would depend on partition coefficient $\mathrm{K}$. The partition coefficients of itraconazole between the oils and aqueous phase (phosphate buffer $\mathrm{pH}$ 7.4) were found lower when oils containing benzyl alcohol. Equation-2 shows that lower the value of partition coefficient the higher would be the fraction of drug in aqueous phase, $f$ and the faster would be the rate of absorption (from eq.-3).Thus theoretically transcorneal permeation of itraconazole from castor oil should be enhanced and diminished from kardi oil. Our studies on transcorneal permeation of itraconazole from each of the oil drops confirmed the same and maximum permeation was observed from castor oil drops and minimum from kardi oil drops. Thus, the results of the permeation experiments correlate well with the partitioning characteristics of itraconazole.

The major advantages of an ointment dosage form over an aqueous suspension or solution is the possibility of increased contact time and prolonged effect. The major disadvantage is the mixing problem between the ointment vehicle and tears which may limit the penetration rate.[21] Ophthalmic ointment of itraconazole $(0.1 \% \mathrm{w} / \mathrm{w})$ was prepared by using both process mentioned in IP and itraconazole ointment $(0.5 \%$ $\mathrm{w} / \mathrm{w})$ was prepared by process- 1 .

Table 5.In Vitro transcorneal permeation of itraconazole from ophthalmic ointments containing $0.1 \% \mathrm{w} / \mathrm{w}$ and

\begin{tabular}{lcccccc}
\hline Formulations & \multicolumn{3}{c}{ Goat cornea } & \multicolumn{3}{c}{$0.5 \% \mathrm{w} / \mathrm{w}$ itraconazole } \\
\cline { 2 - 7 } & $\begin{array}{c}\text { Amount } \\
\text { permeated } \\
(\mathrm{mg} / 120 \mathrm{~min})\end{array}$ & $\begin{array}{c}\text { Permeation } \\
(\%)\end{array}$ & $\begin{array}{c}\text { Corneal } \\
\text { hydration } \\
(\%)\end{array}$ & $\begin{array}{c}\text { Amount } \\
\text { permeated } \\
(\mathrm{mg} / 120 \mathrm{~min})\end{array}$ & $\begin{array}{c}\text { Permeation } \\
(\%)\end{array}$ & $\begin{array}{c}\text { Corneal } \\
\text { hydration } \\
(\%)\end{array}$ \\
\hline Type A & 0.0228 & 4.99 & 78.09 & 0.0215 & 4.70 & 77.91 \\
$(0.1 \% \mathrm{w} / \mathrm{w})$ & \pm 0.0014 & \pm 0.32 & \pm 0.14 & \pm 0.0018 & \pm 0.24 & \pm 0.24 \\
Type B & 0.0327 & 7.15 & 79.28 & 0.0296 & 6.48 & 79.12 \\
$(0.1 \% \mathrm{w} / \mathrm{w})$ & \pm 0.0011 & \pm 0.23 & \pm 0.31 & \pm 0.0099 & \pm 0.19 & \pm 0.38 \\
Type A & 0.0391 & 1.66 & 78.12 & 0.0374 & 1.59 & 78.65 \\
$(0.5 \% \mathrm{w} / \mathrm{w})$ & \pm 0.0018 & \pm 0.08 & \pm 0.49 & \pm 0.0074 & \pm 0.03 & \pm 0.24 \\
\hline
\end{tabular}

Values are mean \pm SD of three observations in each group.

Table 5 indicates the permeation of itraconazole from $0.1 \% \mathrm{w} / \mathrm{w}$ and $0.5 \% \mathrm{w} / \mathrm{w}$ ointment formulations through goat and sheep corneas. The amount permeated of itraconazole $(0.0327 \pm 0.0011 \mathrm{mg}, 0.0296 \pm 0.0 .0099 \mathrm{mg})$ from ointment (type-B, $0.1 \% \mathrm{w} / \mathrm{w}$ ) containing dissolved drug was higher than the ointment containing solid itraconazole dispersed in the ointment base through goat and sheep corneas respectively. When solid drug in finely divided state is dispersed in the ointment base, release of drug depends on dissolution and diffusion. Thus, permeation of itraconazole from ointment containing itraconazole in solution form could be higher as dissolution of drug was no more needed. Increase in drug concentration from $0.1 \% \mathrm{w} / \mathrm{v}$ to $0.5 \% \mathrm{w} / \mathrm{v}$ in ointment type-A resulted in increase in amount of drug permeated, but decrease in percentage permeation, indicating concentration dependent permeation. Corneal hydration level (after 2 hours permeation) obtained with ointment were in the normal range below $80 \%$. Ointment containing aqueous solution of drug showed higher corneal hydration in both goat and sheep corneas.

The antifungal activity of the oil drops against Candida albicans was evaluated. The diameters of clear zone of inhibition are shown in figure $1 \& 2$. The castor oil formulation showed maximum zone of inhibition. The results of accelerated stability study conducted on oily itraconazole solutions for a period of six months are 
shown in table 6. Neither any significant loss in drug concentration nor any color change was found in the formulations during the six months storage period. Thus, the formulations appear to be quite stable to ensure two years shelf life.

Table 6.Stability of itraconazole in oily ophthalmic solutions under accelerated storage conditions (six months)

\begin{tabular}{|c|c|c|c|c|c|c|c|c|c|c|}
\hline \multirow{2}{*}{$\begin{array}{c}\text { Formu } \\
\text { lation } \\
\text { code }\end{array}$} & \multirow[t]{2}{*}{ Oil } & \multirow{2}{*}{$\begin{array}{c}\text { Benz } \\
\text { yl } \\
\text { alcoh } \\
\text { ol (\% } \\
\text { w/v) }\end{array}$} & \multicolumn{4}{|c|}{ Itraconazole content } & \multicolumn{4}{|c|}{ Appearance (color) } \\
\hline & & & $0 \mathrm{D}$ & $6 \mathrm{~W}$ & $3 \mathrm{M}$ & $6 \mathrm{M}$ & $0 \mathrm{D}$ & $6 \mathrm{~W}$ & $3 \mathrm{M}$ & $6 \mathrm{M}$ \\
\hline OI1 & Arachis & $* * *$ & $102.1 \pm 0.15$ & $101.85 \pm 0.51$ & $100.2 \pm 0.23$ & $98.06 \pm 0.6$ & L Y & L Y & L Y & L Y \\
\hline OI $1 b$ & Arachis & 0.5 & $102.11 \pm 0.1$ & $101.92 \pm 0.22$ & $99.6 \pm 0.5$ & $97.25 \pm 0.54$ & L Y & L Y & L Y & L Y \\
\hline OI 2 & Castor & **** & $101.3 \pm 0.2$ & $101.1 \pm 0.16$ & $99.83 \pm 0.6$ & $96.98 \pm 0.35$ & L Y & L Y & L Y & L Y \\
\hline OI $2 b$ & Castor & 0.5 & $101.2 \pm 0.1$ & $100.67 \pm 0.28$ & $97.77 \pm 0.4$ & $95.61 \pm 0.7$ & L Y & L Y & L Y & L Y \\
\hline OI 3 & Cottonseed & $* * *$ & $98.0 \pm 0.3$ & $98.0 \pm 0.32$ & $97.1 \pm 0.45$ & $96.35 \pm 0.5$ & L Y & L Y & L Y & L Y \\
\hline OI $3 b$ & Cottonseed & 0.5 & $98.0 \pm 0.4$ & $97.9 \pm 0.15$ & $96.69 \pm 0.1$ & $95.82 \pm 0.4$ & L Y & L Y & L Y & L Y \\
\hline OI 4 & Kardi & *** & $102.6 \pm 0.25$ & $102.36 \pm 0.21$ & $101.77 \pm 0.3$ & $98.6 \pm 0.6$ & L Y & L Y & L Y & L Y \\
\hline $\mathrm{OI} 4 \mathrm{~b}$ & Kardi & 0.5 & $102.5 \pm 0.25$ & $102.23 \pm 0.24$ & $100.78 \pm 0.5$ & $97.81 \pm 0.3$ & L Y & L Y & L Y & L Y \\
\hline OI 5 & Linseed & $* * *$ & $100.9 \pm 0.14$ & $100.8 \pm 0.32$ & $99.09 \pm 0.3$ & $97.85 \pm 0.15$ & $\mathrm{Y}$ & $\mathrm{Y}$ & $\mathrm{Y}$ & $\mathrm{Y}$ \\
\hline $\mathrm{OI} 5 \mathrm{~b}$ & Linseed & 0.5 & $100.9 \pm 0.12$ & $100.55 \pm 0.25$ & $99.25 \pm 0.3$ & $97.13 \pm 0.4$ & $\mathrm{Y}$ & $\mathrm{Y}$ & $\mathrm{Y}$ & $\mathrm{Y}$ \\
\hline OI 6 & Sesame & *** & $98.8 \pm 0.34$ & $98.6 \pm 0.34$ & $96.88 \pm 0.3$ & $95.43 \pm 0.4$ & $\mathrm{~L} \mathrm{Y}$ & L Y & L Y & L Y \\
\hline OI $6 b$ & Sesame & 0.5 & $98.85 \pm 0.4$ & $98.62 \pm 0.2$ & $97.36 \pm 0.5$ & $96.44 \pm 0.3$ & L Y & L Y & L Y & L Y \\
\hline OI 7 & Soybean & $* * *$ & $99.3 \pm 0.2$ & $99.12 \pm 0.36$ & $98.23 \pm 0.4$ & $96.67 \pm 0.6$ & $\mathrm{~L} \mathrm{Y}$ & L Y & L Y & $\mathrm{L} \mathrm{Y}$ \\
\hline OI $7 b$ & Soybean & 0.5 & $99.25 \pm 0.2$ & $98.92 \pm 0.65$ & $98.03 \pm 0.2$ & $97.27 \pm 0.4$ & L Y & L Y & L Y & L Y \\
\hline OI 8 & Olive & $* * *$ & $99.2 \pm 0.3$ & $98.82 \pm 0.2$ & $97.54 \pm 0.5$ & $96.46 \pm 0.3$ & $\mathrm{Y}$ & $\mathrm{Y}$ & $\mathrm{Y}$ & $\mathrm{Y}$ \\
\hline OI $8 b$ & Olive & 0.5 & $99.23 \pm 0.3$ & $98.89 \pm 0.3$ & $97.75 \pm 0.4$ & $96.32 \pm 0.5$ & $\mathrm{Y}$ & $\mathrm{Y}$ & $\mathrm{Y}$ & $\mathrm{Y}$ \\
\hline OI 9 & Sunflower & $* * *$ & $98.94 \pm 0.3$ & $98.68 \pm 0.23$ & $97.18 \pm 0.2$ & $96.41 \pm 0.6$ & L Y & L Y & L Y & L Y \\
\hline OI $9 b$ & Sunflower & 0.5 & $98.96 \pm 0.2$ & $98.66 \pm 0.24$ & $97.31 \pm 0.3$ & $96.33 \pm 0.3$ & L Y & L Y & L Y & L Y \\
\hline
\end{tabular}

Values are mean $\pm \mathrm{SD}(\mathrm{n}=3)$. D: days, W: weeks, M: months, Y: yellow, LY: light yellow

Figure 5. Graph of zone of inhibition of oil drop formulations against Candida albicans.

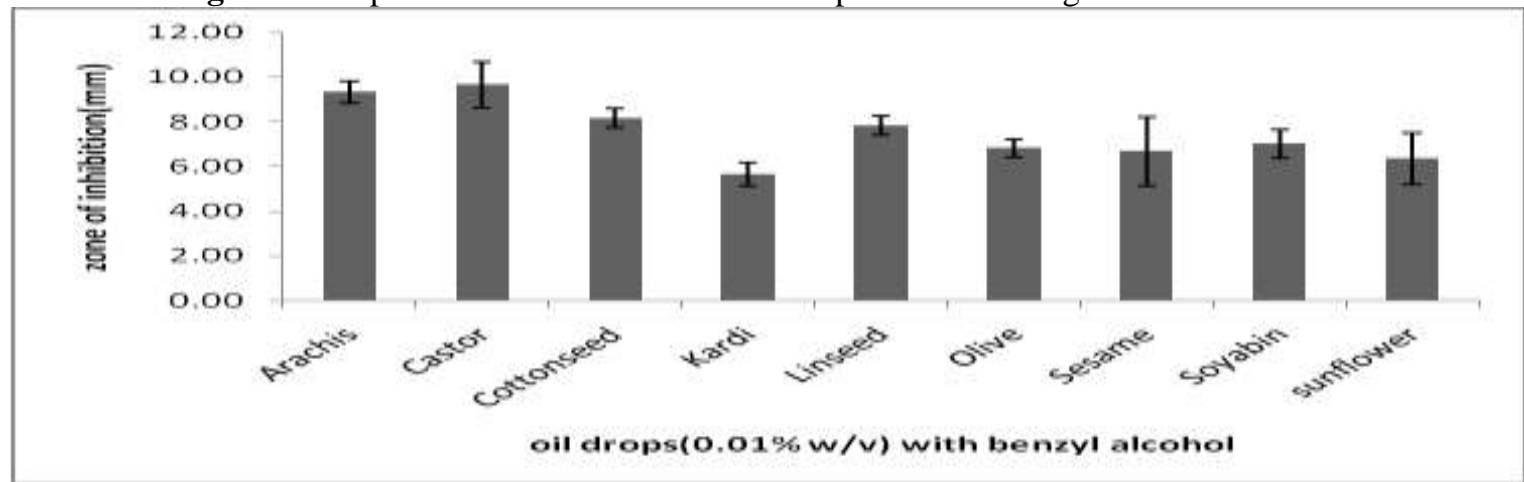

Figure 6. Photograph of zone of inhibition of castor oil drop against Candida albicans.
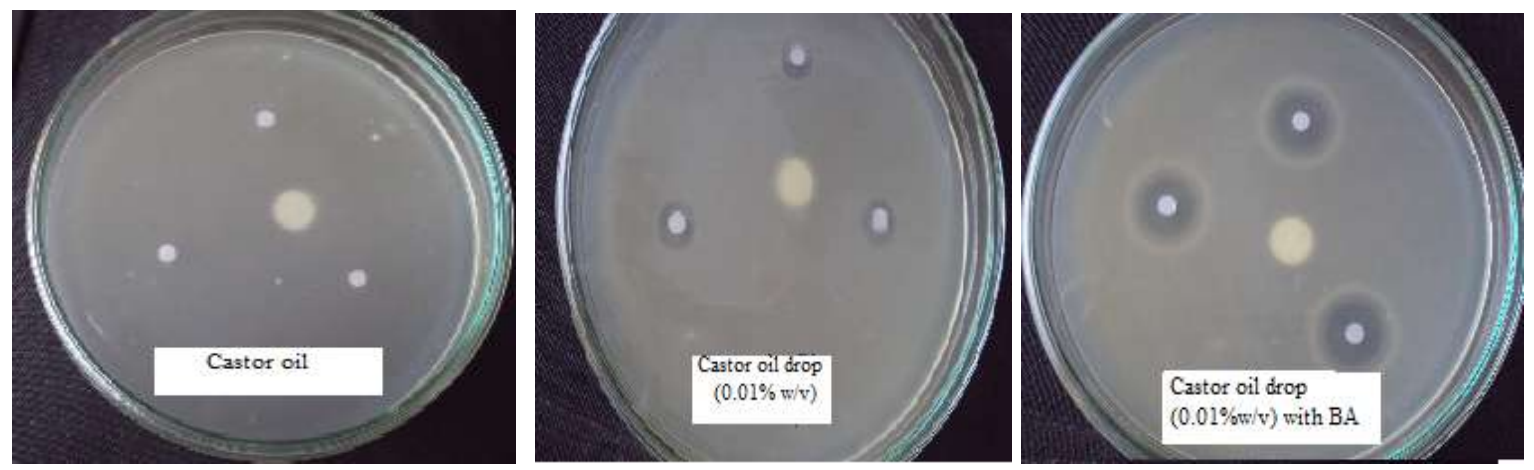


\section{Conclusion}

Based on the present study, it can be concluded that itraconazole $0.01 \%(\mathrm{w} / \mathrm{v})$ solution in castor oil provides maximum permeation through both goat and sheep corneas. Addition of benzyl alcohol to oil drops increases drug permeation due to increased partitioning of drug to the aqueous phase. Addition of phenyl mercuric acetate, phenyl mercuric nitrate and thiomersal into castor oil formulation reduced permeation through both goat and sheep corneas. Ointment base containing aqueous solution of voriconazole provides maximum percentage permeation through both goat and sheep cornea. Clear zone of inhibition revealed the microbial efficacy of the itraconazole oil drops. Stability study conducted at $40^{\circ} \mathrm{C}$ with $70 \% \mathrm{RH}$ indicated the formulations as quite stable to ensure 2 years shelf life.

\section{Acknowledgements}

Authors are thankful to Jubilant Organosys Ltd., New Delhi India for donating the itraconazole bulk drug.

\section{References}

[1] L.Lavin, R.Avery, J.Shore, J.Woog, A.Baker, The spectrum of orbital aspergillus: A clinicopaththological review, Survey of Ophthalmology, 41(2), 1996, 142 - 152.

[2] R. Yohai, J. Bullock, A. Aziz, R. Markert, Survival factors in rhinoorbital-cerebral mucormycosis, Survey of Ophthalmology, 39(1), 1994, 3-22.

[3] J. See, T. Wong, K. Yeo, Trends in the pattern of blindness and major ocular diseases in Singapore and Asia. Annals Academy of Medicine, Singapore, 27(4), 1998, 540-546.

[4] K.J. Johns, D.M. O'Day, Pharmacologic management of keratomycosis. Survey of Ophthalmology, 33, 1988, $178-188$.

[5] D.M.O'Day, Selection of appropriate antifungal therapy, Cornea, 6, 1987, 238-245.

[6] D.B. Jones, Decision making in the management of microbial keratitis. Ophthalmology, 88, 1981, 814-820.

[7] R.K.Forster, The Cornea (Scientific Foundation and Clinical Practice. Boston, Little Brown \& Co) 1987, 228-240.

[8] K. Richardson, K.W. Brammer, M.S. Marriott, Activity of UK49,858, a bis-Triazole derivative against experimental infections with Candida albicans and Trichophyton mentagrophytes, Antimicrobial Agents and Chemotherpy, 27, 1985, 832-835.

[9] B. Dupont, E. Drouhet, Early experience with itraconazole in vitro and in patients.Pharmacokinetic studies and clinical results, Reviews of Infectious Diseases (Suppl), 9,1987, S71-S76.

[10] N. Davies. Biopharmaceutical considerations in topical ocular drug delivery. Clinical and Experimental Pharmacology and Physiology 27(7), 2000, 558-562.

[11] S.C. Bhojwani, D.K. Jones, Comparative study of aqueous and oily pilocarpine in the production of ocular hypotension, British Journal of Ophthalmology, 65, 1981, 530-532

[12] M. Malhotra, D.K. Majumdar, In vitro transcorneal permeation of ketorolac from oil based ocular drops and Ophthalmic ointment, Indian Journal of Experimental Biology,35,1997, 1324-1330.

[13] M. Malhotra, D.K. Majumdar, In vivo ocular availability of ketorolac following ocular instillations of aqueous, oil, and ointment formulations to normal corneas of rabbit, AAPS Pharmscitech,6, 2005, 65.

[14] M. Ahuja, S.K. Sharma, D.K. Majumdar, In vitro corneal permeation of diclofenac from oil drops, YakugakuZasshi, 127(10), 2007, 1739-1745.

[15] P.K. Pawar, D.K. Majumdar, In vitro permeation characteristics of moxifloxacin from oil drops through excised goat, sheep, buffalo and rabbit corneas, Pharmazie ,62(11), 2007 Nov, 53-7.

[16] M. Malhotra, D.K. Majumdar, In vitro transcorneal permeation of ketorolac tromethamine from buffered and unbuffered aqueous ocular drops, Indian Journal of Experimental Biology,35, 1997, 941-947.

[17] Pharmacopoeia of India (Manager of Publications, Ministry of Health, Government of India, Delhi), $1970,296$.

[18] D.M. Maurice, M.V. Riley, Ocular Pharmacokinetics (In: G raymore CN, ed. Biochemistry of the Eye. London, UK: Academic Press, 1970, 6Y16).

[19] G. Hecht, R.E. Rochrs, E.R. Cooper, J.W. Hiddemen, B.F. Van Duzee, Modern Pharmaceutics Vol. 40, edited by G S Banker \& C T Rhodes (Marcel Dekker Inc., New York). 1990, 569.

[20] S.A. Smith, S.E. Smith and R. Lazare, An increased effect of pilocarpine on the pupil by application of the drug in oil. British Journal of Ophthalmology,62, 1978, 314.

[21] M. Gibaldi, Biopharmaceutics and Clinical pharmacokinetics 3rd edition, (lea \& Febiger, Philadelphia), $1984,96$. 